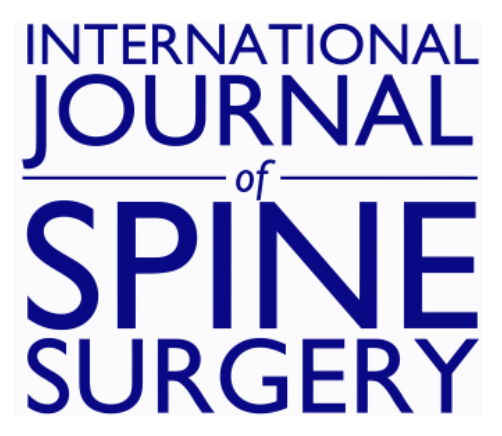

\title{
Single-Level Cervical Disc Replacement Using a PEEK-on-Ceramic Implant: Results of a Multicenter FDA IDE Trial With 24-Month Follow-up
}

Richard D. Guyer, Domagoj Coric, Pierce D. Nunley, Rick C. Sasso, Michael Musacchio, Hyun W. Bae, John H. Peloza and Donna D. Ohnmeiss

Int J Spine Surg 2021, 15 (4) 633-644

doi: https://doi.org/10.14444/8084

http://ijssurgery.com/content/15/4/633

This information is current as of April 25, 2023.

Email Alerts Receive free email-alerts when new articles cite this article. Sign up at: http://ijssurgery.com/alerts 


\title{
Single-Level Cervical Disc Replacement Using a PEEK-on-Ceramic Implant: Results of a Multicenter FDA IDE Trial With 24-Month Follow-up
}

RICHARD D. GUYER, MD, ${ }^{1}$ DOMAGOJ CORIC, MD ${ }^{2}$ PIERCE D. NUNLEY, MD,${ }^{3}$ RICK C. SASSO, MD,${ }^{4}$ MICHAEL MUSACCHIO, MD ${ }^{5}$ HYUN W. BAE, MD, ${ }^{6}$ JOHN H. PELOZA, MD, ${ }^{7}$ DONNA D. OHNMEISS, DrMed $^{1,8}$

${ }^{I}$ Center for Disc Replacement at Texas Back Institute, Plano, Texas, ${ }^{2}$ Carolina Neurosurgery and Spine Associates, Charlotte, North Carolina, ${ }^{3}$ Spine Institute of Louisiana, Shreveport, Louisiana, ${ }^{4}$ Indiana Spine Group, Carmel, Indiana, ${ }^{5}$ NorthShore University Health System, Evanston, Illinois, ${ }^{6}$ The Spine Institute, Los Angeles, California, ${ }^{7}$ Steadman-Hawkins Clinic, Vail, Colorado, ${ }^{8}$ Texas Back Institute Research Foundation, Plano, Texas

\begin{abstract}
Background: Many early cervical total disc replacements (TDRs) produced motion through a ball-and-socket action, with metal endplates articulating with a plastic core. Polyetheretherketone (PEEK) is used increasingly for spinal implants due to its mechanical properties and lack of artifacts on imaging. A TDR was designed with titanium-coated PEEK endplates and a ceramic core. The purpose of this study was to compare this TDR with anterior cervical discectomy and fusion (ACDF) to treat single-level cervical disc degeneration.

Methods: This was a prospective, nonrandomized, historically controlled, multicenter US Food and Drug Administration (FDA) Investigational Device Exemption (IDE) trial. Patients received the PEEK-on-ceramic Simplify Cervical Artificial Disc $(\mathrm{n}=150)$. The historic control group included 117 propensity-matched ACDF patients from an earlier IDE trial. The primary outcome was a composite success classification at the 24-month follow-up. Outcome measures included the Neck Disability Index (NDI), neurological status, adverse events, subsequent surgery, a visual analog scale assessing neck and arm pain, and the Dysphagia Handicap Index. Radiographic assessment included flexion/extension range of motion and heterotopic ossification. Facet joints were assessed at 24 months using MRI.

Results: The success rate was significantly greater in the TDR group vs the ACDF group $(93.0 \%$ vs $73.6 \% ; P<$ .001). Mean NDI, neck pain, and arm pain scores improved significantly in both groups at all follow-up points. Mean NDI scores in the TDR group were significantly lower than ACDF scores at all follow-up points. There were no significant differences in the rates of serious adverse events. The range of motion of the TDR level had increased significantly by 3 months and remained so throughout follow-up. Facet joint assessment by MRI in the TDR group showed little change from preoperation.

Conclusions: The TDR had an acceptable safety profile and a significantly greater composite success rate than ACDF. These results support that the PEEK-on-ceramic TDR is a viable alternative to ACDF for single-level symptomatic disc degeneration.
\end{abstract}

Clinical Relevance: This study found that the PEEK-on-ceramic TDR is a viable treatment for symptoms related to cervical disc degeneration and offers similar or superior outcomes compared with fusion.

Level of Evidence: 2.

Total Disc Replacement

Keywords: disc replacement, cervical spine, FDA IDE trial, PEEK-on-ceramic device, clinical outcome

\section{INTRODUCTION}

There have been multiple prospective, randomized, controlled trials comparing cervical total disc replacement (TDR) and anterior cervical discectomy and fusion (ACDF). Multiple meta-analyses of these and other studies have found that TDR produces outcomes superior to ACDF. ${ }^{1-3}$ The first cervical TDRs used on a large-scale basis produced motion through a ball-and-socket or mobile-bearing action, with metal endplates articulating with a plastic core. Various designs followed including metal-on-metal devices and a titanium-ceramic composite device, as well as a compressible disc with metal endplates. The use of polyetheretherketone (PEEK) material for spinal implants continues to increase, primarily due to its mechanical properties and lack of producing artifacts on imaging studies. ${ }^{4,5}$ Though less extensive than cervical fusion 

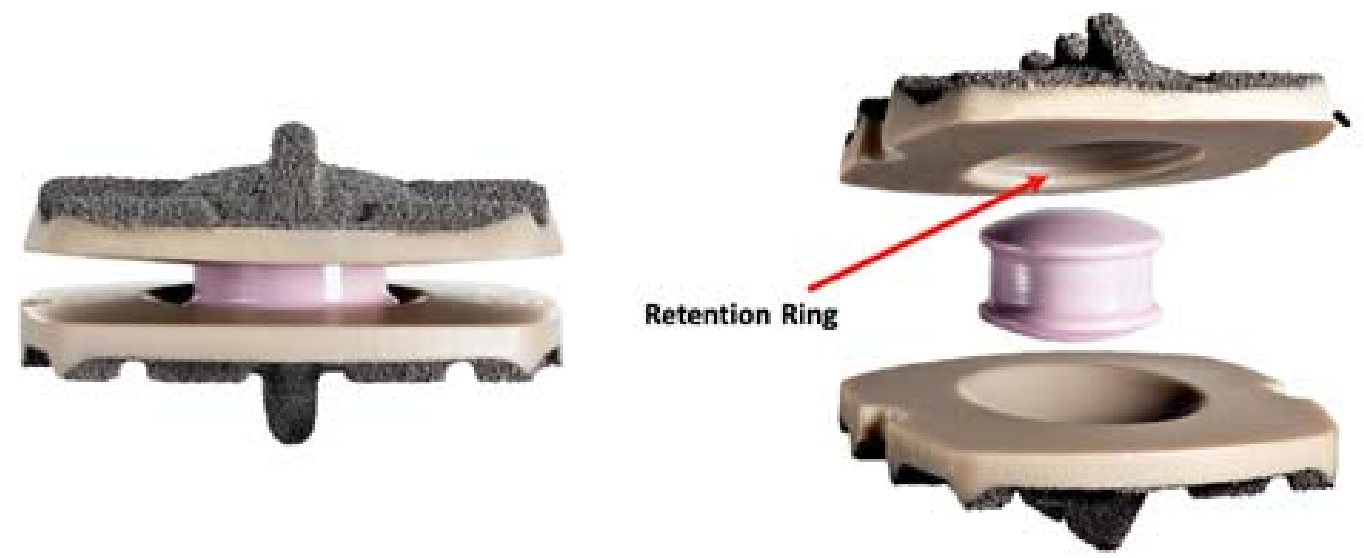

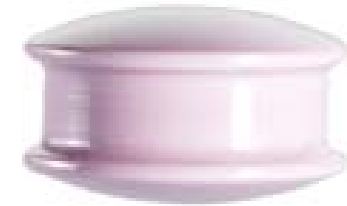

Biconvex Core

Figure 1. The PEEK-on-ceramic device investigated in the current study. The PEEK endplates are coated with plasma-spray titanium and the core is ceramic (image courtesy of Simplify Medical, with permission).

cages, there has been investigation into the use of PEEK for cervical TDR. ${ }^{6-12}$ Despite general optimism, there was concern about long-term degradation on articulating PEEK-on-PEEK surfaces. ${ }^{10}$ This may be particularly problematic and cause uneven loading if the implant is not ideally positioned. Another concern with PEEK is the bioinert surface. However, this has been addressed in many implants by adding a textured porous coating, often titanium, a material with favorable osseointegrative properties. ${ }^{5,13,14}$ A cervical TDR was designed with commercially pure, titaniumcoated PEEK endplates and a biconvex zirconiatoughened alumina ceramic core. This ceramic material has long been used in orthopedic applications, particularly hip implants. ${ }^{15}$ Biomechanical analysis of the PEEK-on-ceramic device found an acceptable wear profile with no evidence of runaway wear, endplate perforation, or component fracture in idealized or aggressive wear simulation testing. ${ }^{8}$ The purpose of the study was to compare the PEEK-on-ceramic TDR to ACDF for the treatment of cervical disc degeneration at a single level.

\section{METHODS}

\section{Device}

The Simplify ${ }^{\circledR}$ Cervical Artificial Disc (Nuvasive, Inc.; San Diego, CA) comprises PEEK endplates and a mobile zirconia-toughened alumina ceramic core (Figure 1). The endplates have a commercially pure titanium coating. The articulating surfaces on the endplates have a concave surface, and the core has two convex surfaces. The superior and inferior endplates are available in 3 footprints (small, medium, large), 3 thicknesses resulting in 3 device heights $(4,5$, and $6 \mathrm{~mm})$, and 2 lordosis angles, $0^{\circ}$ and $5^{\circ}$. The superior endplate has a retention ring feature to retain the core within the endplates. The 4-mm device, which became available after approximately $13 \%$ of patients were enrolled, was used in $39 \%$ of study patients, the $5-\mathrm{mm}$ in $53 \%$, and the $6-\mathrm{mm}$ in $8 \%$ of patients. With respect to the lordosis of the implants, the $0^{\circ}$ implant was used in $85 \%$ of patients and the $5^{\circ}$ implant in the remaining $15 \%$.

\section{Patient Selection and Study Design}

This study was a prospective, nonrandomized, historically controlled, multicenter trial. It was based on the US Food and Drug Administration (FDA) Investigational Device Exemption (IDE) trial for the PEEK-on-ceramic cervical TDR. Data were collected prospectively for 150 study patients from 16 sites (after 16 training cases). Patient selection criteria are provided in Table 1. Outcomes were compared with data collected for 117 historical ACDF control subjects treated at 21 sites as part of a previous IDE TDR trial. ${ }^{16}$ The inclusion/exclusion criteria used were the same as those used in the current study. At the time of study initiation, several cervical TDR devices were approved for use in the United States. It was thought that this would make it difficult to enroll patients into a randomized study comparing TDR with ACDF. A statistical plan, discussed with and accepted by the FDA, using propensity score (PS) modeling was developed to incorporate the historical ACDF control and to match the baseline covariates to the investigational TDR group. The propensity matching led to the inclusion of all 150 TDR patients enrolled in the trial and 117 of the 133 historical control subjects 
Table 1. Inclusion and exclusion criteria.

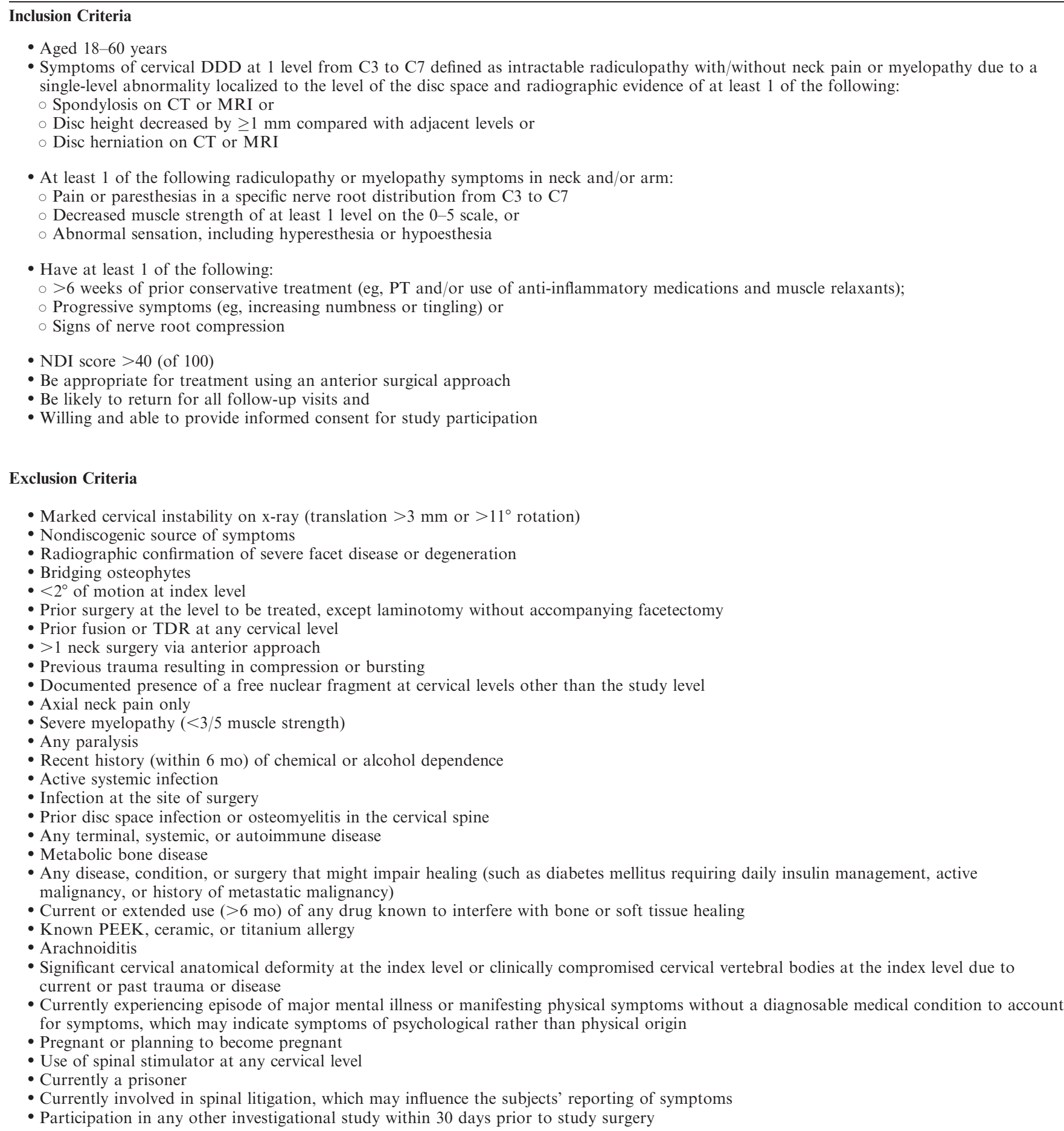

Abbreviations: CT, computed tomography; DDD, degenerative disc disease; PEEK, polyetheretherketone; PT, physical therapy; TDR, total disc replacement.

available for matching (Figure 2). The TDR patients and PS-selected historical control patients had approximately the same multivariate baseline covariate distribution. Table 2 provides an overview of the 2 groups. All patients were treated for singlelevel symptomatic cervical degenerative disc disease
(DDD), defined as intractable cervical radiculopathy with or without neck pain, or with myelopathy. The control group was treated with ACDF using an anterior plate system (DePuy Spine's VG2 allograft bone and Slim-Loc spinal system) and corticocancellous allograft bone. 


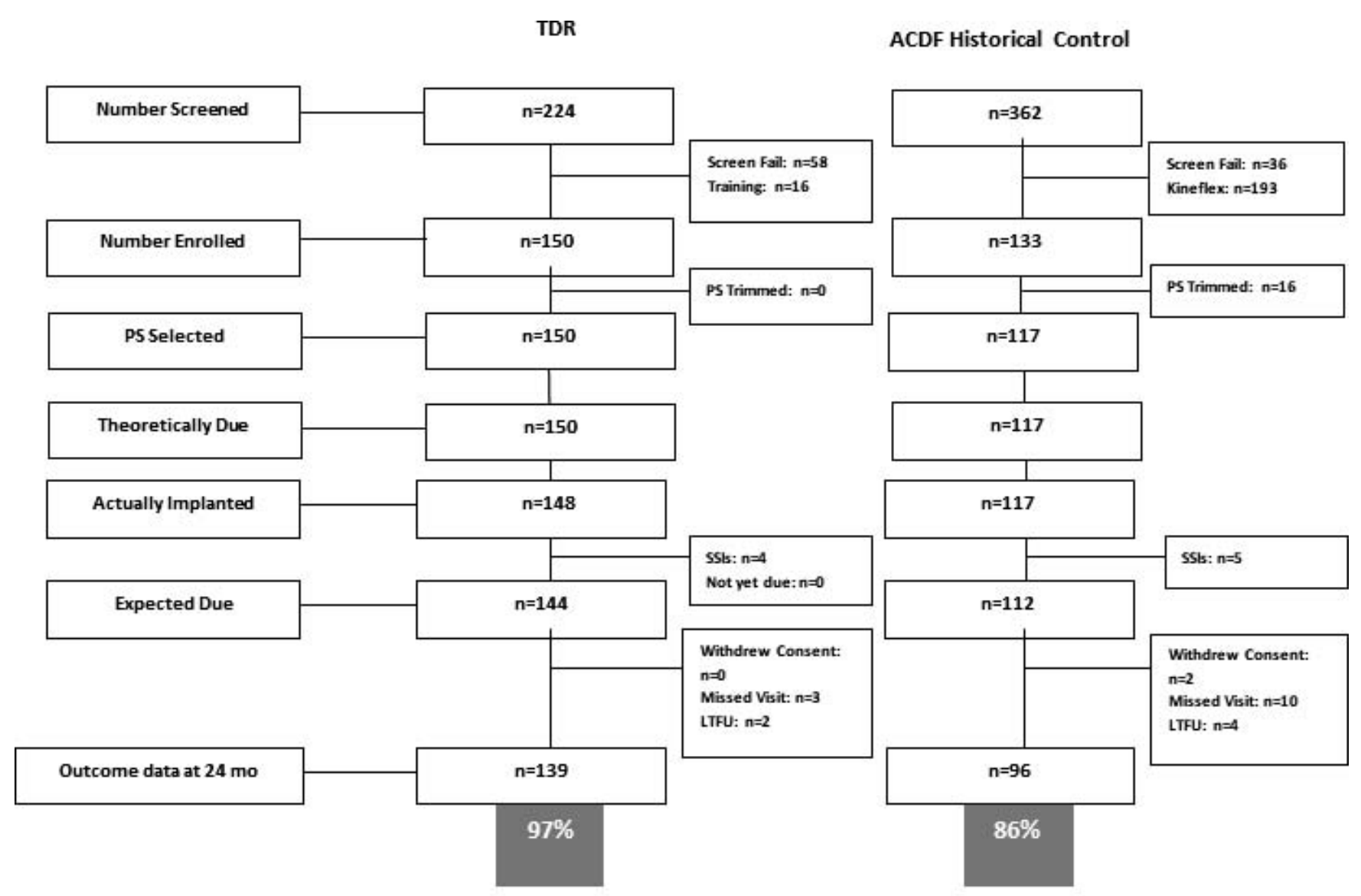

Abbreviations: PS: Propensity scoring; SSI: Secondary Surgical Intervention; LTFU: lost to follow-up

Figure 2. The derivation of the 2 treatment groups.

\section{Outcome Assessment}

Patients were evaluated prior to surgery and postoperatively within 2 weeks, 6 weeks, and 3, 6, 12, and 24 months. Patient-completed assessments included the Neck Disability Index (NDI), visual analog scale (VAS) assessing neck and arm pain, quality of life (Short Form-12), Dysphagia Handicap Index (DHI), ${ }^{17}$ and patient satisfaction. A neurological examination composed of motor, sensory, and reflex assessments was required for the study. Radiographic assessment was performed

Table 2. Comparison of the TDR and the propensity-matched historical control group. There were no significant differences between the 2 groups.

\begin{tabular}{|c|c|c|c|c|c|c|c|}
\hline & \multicolumn{3}{|c|}{ TDR } & \multicolumn{3}{|c|}{ ACDF } & \multirow[b]{2}{*}{$P$ Value } \\
\hline & $\mathbf{n}$ & Mean & SD & n & Mean & SD & \\
\hline Age, y & 150 & 43.0 & 8.9 & 117 & 44.1 & 7.0 & $>.75$ \\
\hline BMI, $\mathrm{kg} / \mathrm{m}^{2}$ & 150 & 27.5 & 5.2 & 117 & 28.7 & 5.6 & $>.90$ \\
\hline NDI & 150 & 63.3 & 12.5 & 117 & 62.4 & 12.6 & $>.90$ \\
\hline VAS neck and arm pain & 150 & 81.6 & 12.4 & 117 & 77.6 & 13.5 & $>.70$ \\
\hline Disc angle, ${ }^{\circ}$ & 148 & 2.1 & 4.5 & 116 & 2.6 & 4.4 & $>.25$ \\
\hline Disc height, $\mathrm{mm}$ & 148 & 3.3 & 0.7 & 115 & 3.3 & 0.8 & $>.80$ \\
\hline Rotation, $^{\circ}$ & 148 & 7.3 & 4.2 & 110 & 7.3 & 4.4 & $>.55$ \\
\hline \multirow[t]{2}{*}{ Translation, mm } & 143 & 0.7 & 0.5 & 109 & 0.8 & 0.6 & $>.05$ \\
\hline & $\mathbf{n}$ & $\%$ & & $\mathbf{n}$ & $\%$ & & \\
\hline Sex & & & & & & & $>.65$ \\
\hline Female & 91 & 60.7 & & 68 & 58.1 & & \\
\hline Male & 59 & 39.3 & & 49 & 41.9 & & \\
\hline
\end{tabular}

Abbreviations: ACDF, anterior cervical discectomy and fusion; BMI, body mass index; NDI, Neck Disability Index; TDR, total disc replacement; VAS, visual analog scale. 
at each postoperative time point and an MRI was performed at the 24-month follow-up.

The primary study outcome was a clinical composite success (CCS) parameter based on 24month follow-up values requiring (1) at least a 15point (of 100) improvement in NDI score from baseline; (2) maintenance/improvement in neurologic status compared with baseline; (3) no device failures; (4) no reoperation, revision, removal, and/ or supplemental fixation at the index level, and (5) absence of major adverse events (AEs; defined as definite device relationship that caused permanent neurologic damage related to treated level or below or implant breakage/migration without index level surgery that caused significant dysphagia and/or death).

\section{$\mathrm{AE}$ Evaluation}

A clinical events committee composed of 3 independent spine surgeons was responsible for the adjudication of AEs (reviewing the relationship to device/procedure, seriousness, severity, determination of major AE, and unanticipated adverse device effects), neurological status, secondary surgical interventions (ie, classification of revision, removal, reoperation, or supplemental fixation), and protocol deviations.

\section{Radiographic and MRI Assessment}

All imaging assessments were performed by an independent lab specializing in image analysis (Medical Metrics, Houston, TX). Flexion/extension, neutral anteroposterior, neutral lateral, and lateral bending radiographs were made at required study evaluation points. Radiographic assessment included segmental flexion/extension range of motion (ROM), disc height, and heterotopic ossification (HO). HO was assessed using a 0 to 4 (none to bridging bone) scale commonly used in TDR studies. ${ }^{18}$

Preoperative and 24-month postoperative MRIs were used to assess the facet joints at the treated level. The facet joints were evaluated using the following classification system. ${ }^{19,20}$

0. None: normal facet joint space

1. Mild: narrowing of the facet joint space and/or small osteophytes and/or mild hypertrophy of the articular process

2. Moderate: narrowing of the facet joint space and/or moderate osteophytes and/or moderate hypertrophy of the articular process and/or mild subarticular bone erosions

3. Severe: narrowing of the facet joint space and/ or large osteophytes and/or sever hypertrophy of the articular process and/or severe subarticular bone erosions and/or subchondral cysts

\section{Data Analysis}

Estimated CCS rates for each treatment group, as well as the treatment group differences and $90 \%$ confidence intervals (CI) for group differences controlling for PS subclass, were determined using a generalized linear model with results expressed on the probability scale. This was accomplished using the SAS software procedure GENMOD (SAS Institute, Cary, NC). The PS-adjusted success rates and standard errors on the probability scale were pooled to determine the standard error of the estimated group difference. The CCS were adjusted for PS subclass and therefore will not match the unadjusted $(\mathrm{x} / \mathrm{N})$ percentages. The lower bound of the $90 \% \mathrm{CI}$ is equivalent to that of the 1 -sided $95 \%$ noninferiority CI. The PS model included main effects and important interactions and squared terms for selected baseline variables, such as age and body mass index.

In the study protocol, the null hypothesis was that the probability of achieving CCS for patients implanted with the TDR was no more than .10 smaller than the probability of ACDF control patients achieving CCS. This study would be considered a success if the PS-quintile adjusted, multiple imputation-based, 1 -sided $P$ value for rejecting this null hypothesis was less than .05 . If the noninferiority study success criterion was met, superiority would be tested. If the PS-quintile adjusted 1-sided $P$ value determined from the multiple imputation was less than .05 , it would be concluded that TDR was superior to ACDF.

The primary analysis set includes all TDR patients $(n=150)$ and controls selected into a PS subclass $(\mathrm{n}=117)$. Of 150 TDR patients, 142 (94.7\%) were evaluable for CCS. Among 117 historical controls, $96(82.1 \%)$ were evaluable for primary CCS endpoint. To account for missing data, a fully conditional specification ${ }^{21}$ approach was used to produce 20 multiply imputed (MI) ${ }^{22}$ completed data sets on the basis of PS subclass and CCS endpoints determined at intermediate time 
Table 3. Comparison of the overall composite success score and the individual components of the composite success in the TDR group and the control fusion group.

\begin{tabular}{|c|c|c|c|c|c|c|c|}
\hline \multirow[b]{2}{*}{ Outcome } & \multicolumn{3}{|c|}{ TDR } & \multicolumn{3}{|c|}{ ACDF } & \multirow[b]{2}{*}{$P$ Value ${ }^{\text {a }}$} \\
\hline & n Assessed & n Success & $\% \mathbf{o}^{\mathbf{b}}$ & n Assessed & n Success & $\%^{\mathbf{b}}$ & \\
\hline Composite success & 150 & $\mathrm{c}$ & 93.0 & 117 & $\mathrm{c}$ & 73.6 & $<.001$ \\
\hline NDI success ${ }^{\mathrm{d}}$ & 138 & 135 & 97.9 & 96 & 83 & 88.0 & $<.01$ \\
\hline Neuro success ${ }^{\mathrm{d}}$ & 139 & 138 & 99.6 & 95 & 90 & 94.1 & $<.02$ \\
\hline No additional surgery ${ }^{\mathrm{e}}$ & 148 & 144 & 97.1 & 117 & 112 & 97.1 & .98 \\
\hline No device failure $\mathrm{df}^{\mathrm{f}}$ & 137 & 137 & 100.0 & 90 & 83 & 92.2 & \\
\hline No major AEs ${ }^{\mathrm{d}}$ & 150 & 150 & 100.0 & 117 & 117 & 100.0 & \\
\hline
\end{tabular}

Abbreviations: ACDF, anterior cervical discectomy and fusion; AEs, adverse events; NDI, Neck Disability Index; TDR, total disc replacement.

${ }^{a}$ Treatment group differences adjusting for propensity score (PS) subclass using 2-way generalized linear model

${ }^{b}$ Equally weighted PS adjusted within-group proportion. This will not equal $\mathrm{n} / \mathrm{N}$, which is the observed data.

${ }^{\mathrm{c}}$ The composite success endpoint was calculated using multiple imputations, generating 20 complete datasets. The percentage shown is the average of the imputations that come from the imputation model and is adjusted for the variables in the imputation model.

${ }^{\mathrm{d}}$ Subjects were censored at index level secondary surgical interventions and intraoperative deviations.

ePropensity score treated as continuous variable to promote convergence.

${ }^{\mathrm{f}}$ Not estimable due to zero cell. Unadjusted within-group rate shown.

points as implemented in the SAS software procedure MI. Group comparisons in secondary endpoints also controlled for PS subclass. Within-group descriptive summaries (not adjusted for PS) included means and standard deviations for continuous variables and counts and percentages for categorical variables. Nominal 95\% PS-adjusted CIs and $P$ values were reported for selected secondary endpoints. Data were censored following a secondary surgical intervention (SSI) and intraoperative deviation at the index level.

\section{RESULTS}

\section{Clinical Outcome}

On the primary outcome evaluation, overall composite success based on the 5-point combined success criteria at the 24-month follow-up, the success rate was significantly greater in the TDR group than in the ACDF control group $(93.0 \%$ vs $73.6 \% ; P<.01$ [PS adjusted]; Table 3) and superiority criteria were met. When comparing the success rates on each of the individual parameters included in the composite assessment, the TDR group had significantly greater rates on NDI success and neurological status success. There was not a statistical difference between groups on the assessments of no additional surgery. Statistical assessment between groups was not estimable for no device failures, and no major AEs. The TDR had similar or better success rates on all criteria parameters, compared with ACDF.

\section{Neck Disability Index}

The mean preoperative NDI scores were similar in the TDR and ACDF groups (Figure 3). The mean NDI scores in both groups were improved significantly at all follow-up points $(P<.001)$ The mean NDI scores in the TDR group were significantly less than in the fusion group at all follow-up points (all $P<.025$ ). The mean change from baseline at 24 months was $-49.4(P<.001 ; 95 \%$ CI, -46.6 to -52.2$)$ in TDR group and $-38.9(P<.001$; $95 \% \mathrm{CI},-34.7$ to -43.1$)$ in the ACDF group. At the 24-month follow-up, significantly more TDR patients achieved the criteria to be classified as reaching clinically relevant improvement on the NDI ( $\geq 15$-point decrease $97.9 \%$ vs $88.0 \% ; P<$ $.05)$.

\section{Visual Analog Scale}

The mean VAS neck and arm pain scores were similar in the TDR and ACDF groups prior to surgery and improved significantly in both groups at all follow-up points (all $P<.001$; Figure 4 ). At the 3-, 6-, and 24-month follow-up points, the scores were significantly less in the TDR group $(P<.05)$. The mean change from baseline at 24 months was

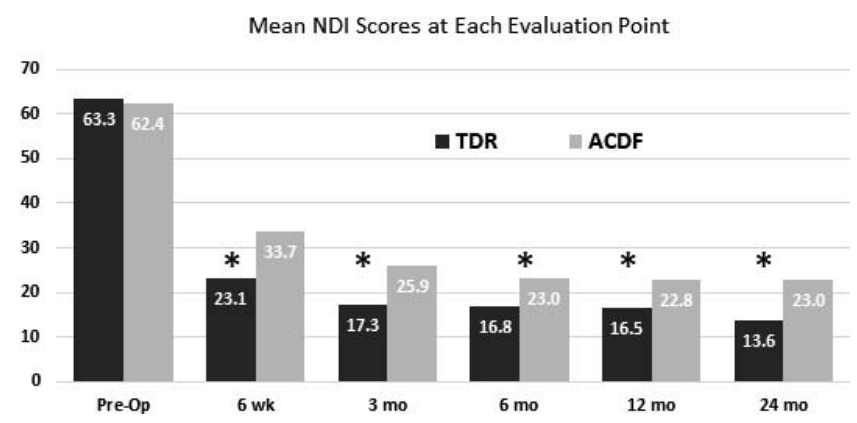

Figure 3. The mean Neck Disability Index (NDI) scores were similar in the 2 groups prior to surgery and were significantly improved throughout follow-up in both groups $(P<.001)$, with the total disc replacement (TDR) group having significantly lower scores at all follow-up points $\left({ }^{*} P<.025\right.$; propensity score [PS] adjusted). Subjects were censored at index-level secondary surgical interventions and intraoperative deviations. 


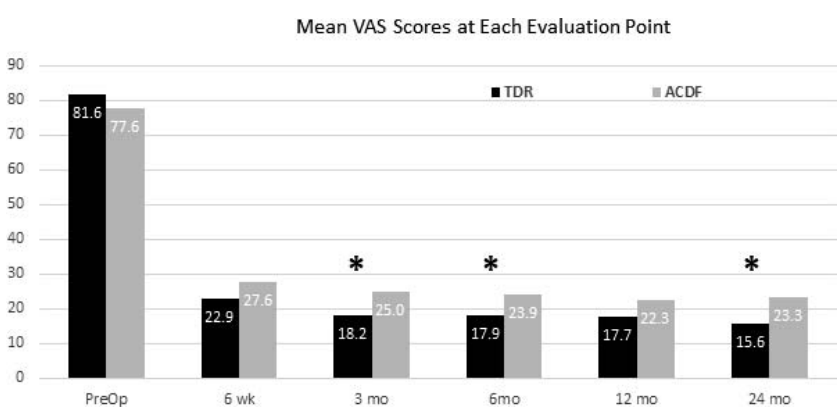

Figure 4. The mean visual analog scale (VAS) neck and arm pain scores were similar in the 2 groups prior to surgery and were significantly improved at all follow-up points $(P<.001)$. The mean scores in the total disc replacement (TDR) group were statistically significantly less than ACDF values at the 3-, 6-, and 24-month follow-ups $(P<.05$, propensity score $[\mathrm{PS}]$ adjusted). Subjects were censored at index level secondary surgical interventions and intraoperative deviations.

$-66.4(P<.001 ; 95 \% \mathrm{CI},-62.7$ to -70.0$)$ in the TDR group and $-53.7(P<.001 ; 95 \% \mathrm{CI},-48.3$ to -59.1) in the ACDF group.

\section{Dysphagia Handicap Index}

The mean DHI score in the TDR group was 6.2 prior to surgery and increased to 7.0 at the 6-week follow-up. By 3 months after surgery, the mean value had decreased to 4.2 and remained near this value throughout follow-up. The DHI was not administered in the ACDF historic control group.

\section{Neurological Evaluation}

Neurological success was defined as maintenance or improvement in neurologic status at the 24month follow-up compared with the patient's preoperative state. In the TDR group, only 1 patient was classified as a neurological failure, which was significantly fewer than the 5 failures in the ACDF cohort $(0.4 \%$ vs $5.9 \% ; P<.02$ [PS adjusted]).

\section{Secondary Surgical Interventions}

In the TDR group there were no cases of device failure or device migration. Through the 24-month follow-up, there were $4(2.7 \%)$ SSI at the index level in the TDR group and $6(5.1 \%)$ in the ACDF group (1 was not included in overall success and subject accounting because it occurred after the 2year endpoint). In the TDR group, SSIs included the following: 1 patient underwent TDR removal and had ACDF performed due to recurrent stenosis and worsening degeneration; another patient had an esophageal tear during the surgical approach, which led to a deep wound infection treated by device removal, corpectomy at C7, ACDF C6-T1 and posterior fusion C6-T2; the third patient had symptomatic pseudoarthrosis after undergoing reoperation $\mathrm{ACDF}$ at the superior adjacent segment and the TDR level was included in anterior plating; and the fourth patient underwent a decompression at the TDR level to address C7 radiculopathy. In the ACDF group, the 6 SSIs included 2 cases of removal of the anterior plate and insertion of a TDR (not the investigational device; in 1 case due to radiculopathy and pseudoarthrosis in the other); 2 cases of removal of anterior plate and replacement with plating at the index and adjacent segment due to adjacent segment degeneration; and 2 cases of removal of anterior plate and a revised graft and plate (due to graft subsidence in 1 case and pseudoarthrosis in the other).

\section{Adverse Events}

Through the 24-month follow-up, the percentage of patients having AEs classified as definitely device related was $0.7 \%(1 / 150)$ in the TDR group and $0.9 \%(1 / 117)$ in the ACDF group. The TDR patient had 2 events related to implant/joint noise and inflammation. In the ACDF group, the event was related to pseudarthrosis. An overview of all the serious AEs is provided in Table 4. There were no statistically significant differences between the TDR and the ACDF control groups.

\section{Radiographic Assessment}

\section{Range of Motion}

The mean segmental ROM of the treated level in the TDR group was $7.38^{\circ}$ prior to surgery. This increased to $8.6^{\circ}$ at the 3 -month follow-up and continued to improve to $9.6^{\circ}$ at the 24-month follow-up $(P<.001)$. Seen in Figure 5 are flexion/ extension radiographs showing motion of the implanted level at C6-7 at the 24-month follow-up.

\section{Heterotopic Ossification}

At the 24-month follow-up, $7.2 \%$ of TDR patients developed grade 4 (bridging bone) HO (1 patient had grade 3 preoperatively) and an additional 7.9\% had grade 3 severe HO (2 patients had grade 2 preoperatively). All of the patients with grade 3 or 4 HO met the 5-point criteria to be classified as having a clinically successful outcome. 
Table 4. The percentage of patients with SAEs reported in the 2 study groups.

\begin{tabular}{|c|c|c|c|c|c|}
\hline & \multicolumn{2}{|c|}{$\operatorname{TDR}(\mathrm{n}=150)$} & \multicolumn{2}{|c|}{$\operatorname{ACDF}(n=117)$} & \multirow[b]{2}{*}{$P$ Value $^{\mathrm{a}}$} \\
\hline & $\mathbf{n}$ & $\% \mathbf{b}^{\mathbf{b}}$ & $\mathbf{n}$ & $\%^{\mathbf{b}}$ & \\
\hline All events & 16 & 10.7 & 16 & 13.7 & .686 \\
\hline Infection (all other infections - not at cervical surgical site) & 2 & 1.3 & 1 & 0.9 & .826 \\
\hline Pseudoarthrosis & 1 & 0.7 & 1 & 0.9 & .772 \\
\hline Trauma & 1 & 0.7 & 1 & 0.9 & .594 \\
\hline Headache & 1 & 0.7 & 1 & 0.9 & .848 \\
\hline Radiculopathy & 1 & 0.7 & 2 & 1.7 & .779 \\
\hline Psychological illness & 1 & 0.7 & 1 & 0.9 & .365 \\
\hline Pain (narcotic given) & 2 & 1.3 & 3 & 2.6 & .518 \\
\hline Adjacent segment degeneration & 2 & 1.3 & 3 & 2.6 & .341 \\
\hline Surgery at a location other than the spine & 2 & 1.3 & 0 & 0.0 & $\ldots$ \\
\hline Gastrointestinal complications including ileus, nausea, and vomiting & 2 & 1.3 & 0 & 0.0 & $\ldots$ \\
\hline Pneumonia & 1 & 0.7 & 0 & 0.0 & $\ldots$ \\
\hline Spinal stenosis & 1 & 0.7 & 0 & 0.0 & $\ldots$ \\
\hline Inflammation conditions, such as discitis, joint, and other types of inflammation & 1 & 0.7 & 0 & 0.0 & $\ldots$ \\
\hline Esophageal perforation & 1 & 0.7 & 0 & 0.0 & $\ldots$ \\
\hline Infection localized to cervical surgical site & 1 & 0.7 & 0 & 0.0 & $\ldots$ \\
\hline Ischemia & 1 & 0.7 & 0 & 0.0 & $\ldots$ \\
\hline Deep wound infection localized to cervical surgical site & 1 & 0.7 & 0 & 0.0 & $\ldots$ \\
\hline Implant collapse or subsidence & 0 & 0.0 & 1 & 0.9 & $\ldots$ \\
\hline Pain (no narcotic given) & 0 & 0.0 & 2 & 1.7 & $\ldots$ \\
\hline Pulmonary embolism & 0 & 0.0 & 1 & 0.9 & $\ldots$ \\
\hline Thrombosis & 0 & 0.0 & 1 & 0.9 & $\ldots$ \\
\hline Other & 0 & 0.0 & 1 & 0.9 & $\ldots$ \\
\hline Cancer & 0 & 0.0 & 2 & 1.7 & $\ldots$ \\
\hline
\end{tabular}

Abbreviations: ACDF, anterior cervical discectomy and fusion; NDI, Neck Disability Index; SAE, serious adverse event; TDR, total disc replacement.

${ }^{a}$ Adjusting for propensity score (PS) subclass using 2-way generalized linear model; comparisons with $<6$ subjects in each group includes PS as a continuous variable ( $\mathrm{df}=$ 1) for model stability.

${ }^{\mathrm{b}}$ Percentage of subjects experiencing specific event.

\section{Facet Joint Assessment}

Facet joints at the TDR level were assessed on the basis of MRIs made preoperatively and at 24 months postoperatively. As seen in Figure 6, there was little change in the facet joint degeneration scores. Images are provided in Figure 7 comparing preoperative with postoperative MRIs. Facet joints were not assessed in the ACDF control cohort.

\section{DISCUSSION}

This prospective IDE trial with a historical propensity-matched ACDF control group found that the PEEK-on-ceramic TDR had an acceptable safety profile and produced clinical outcomes similar or superior to ACDF through the 24-month follow-up. The PS-adjusted composite success rate of $93.0 \%$ in the TDR group was significantly greater

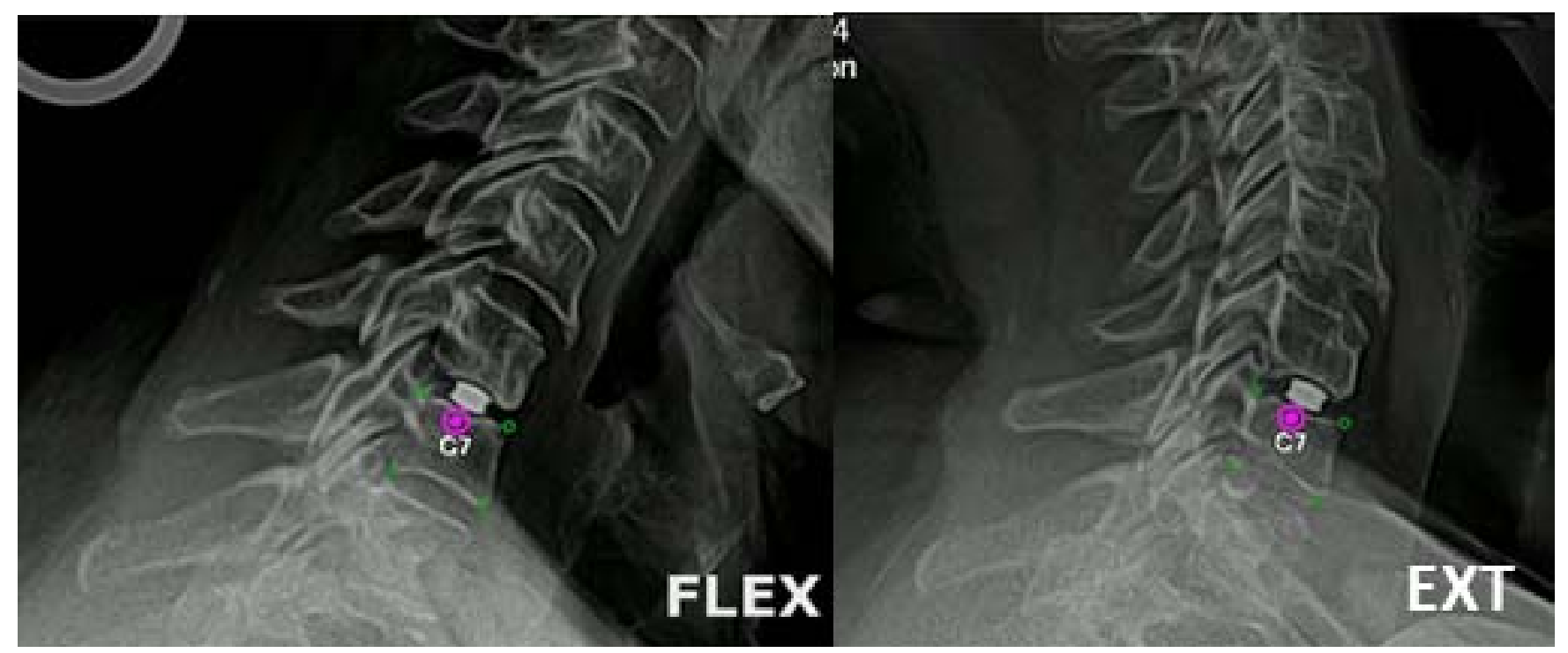

Figure 5. Flexion and extension radiographs from the 24-month follow-up shows the motion of the implant at the C6-7 level. 


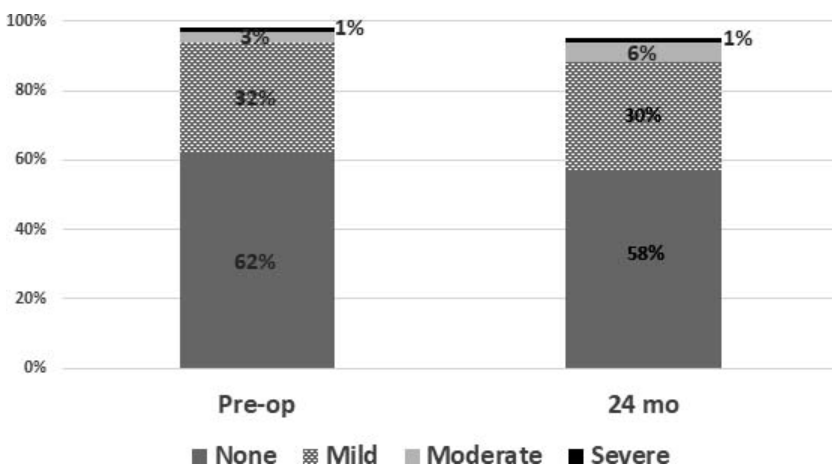

Figure 6. There was little change in the severity of facet joint degeneration at the total disc replacement (TDR) at the 24-month follow-up compared with the preoperative MRls (subjects censored at index level secondary surgical interventions and intraoperative deviations).

than that in the ACDF control group (73.6\%) and met superiority criteria. It was also numerically greater than results reported ${ }^{23-28}$ in other FDAapproved single-level cervical TDR studies using similar composite success criteria, with rates ranging from $72.3 \%$ to $86.8 \%$. There were no TDR device failures or migrations, and there were no complications related to the PEEK-on-ceramic materials.

Unlike the earliest TDR IDE trials, this study was not randomized. Although generally preferable, it was thought that randomization was not feasible with multiple TDRs already FDA approved for use in the United States. Attempting to randomize to ACDF would place patients in the position of potentially receiving fusion, which has been found to be inferior to TDR in meta-analyses. ${ }^{1,29}$ This factor may have made it unduly challenging to recruit patients and/or may have biased the study population. Instead, a group of patients randomized to ACDF in a prior TDR vs ACDF study, using the same selection criteria, many of the same protocol elements, and in fact performed by some of the same surgeons as those participating in the current TDR study were propensity matched to the current TDR population. The study plan was discussed with the FDA and found acceptable. This format of using a propensity-matched ACDF historical control group from an earlier randomized trial has also been used in other recent and pending cervical TDR IDE trials. $^{27,30}$

Several biomechanical studies involving cervical TDR have investigated the potential impact of prosthesis height, particularly with respect to implant sizes that are larger than the natural disc space height. These studies found that increased implant height was associated with decreased $\mathrm{ROM}^{31-33}$ and reduced facet overlap, possibly altering the loading of the adjacent facet joints. These changes could affect the motion of the index level as well as loading of the adjacent segments $^{31,32,34,35}$ and could also be related to the development of $\mathrm{HO}^{36,37}$ One study from China found that in $36 \%$ of the study population, the height of the cervical disc space was less than the minimal height of available TDRs, which is generally $5 \mathrm{~mm} .{ }^{38}$ In analyzing radiographs from an earlier TDR IDE trial, ${ }^{16}$ it was noted that $55 \%$ of adjacent level discs from $\mathrm{C} 3-4$ through $\mathrm{C} 6-7 \mathrm{n}=$ 261) had an average disc height of less than $4 \mathrm{~mm}$ (internal data; Simplify Medical, Sunnyvale, CA), smaller than the minimal prosthesis height available from FDA-approved cervical TDRs. In the current study, $82 \%$ of index levels $(n=164)$ had an average disc height of less than $4 \mathrm{~mm}$ (average of anterior
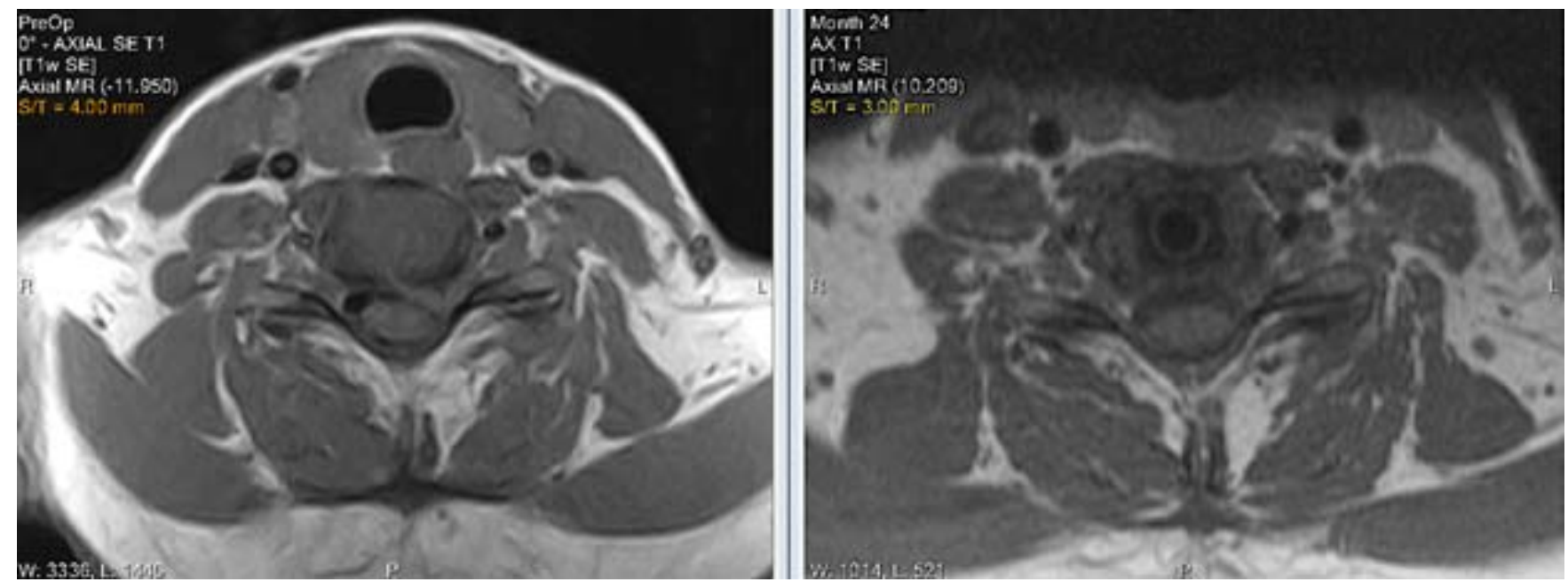

Figure 7. Preoperative and 24-month postoperative MRI of the C6-7 level after total disc replacement (TDR) implantation showing no changes in the facet joints. 
disc height and posterior disc height) and a device of 4-mm height was used in $39 \%$ of patients.

The rate of grade 3 or $4 \mathrm{HO}$ in the current study was $15.1 \%$. This figure is consistent with rates reported at the 24-month follow-up in the summary of safety and effectiveness data reports submitted to the FDA for other cervical TDR devices applying a similar HO scoring system. In these studies, the rates of $\mathrm{HO}$ were $11.3 \%,{ }^{39} 19.2 \%,{ }^{40} 15.9 \%,{ }^{41}$ and $4.3 \%{ }^{42}$ These rates are consistent with a metaanalysis of cervical $\mathrm{HO}$ at the 24-month follow-up reporting a pooled rate of grade 3 or grade $4 \mathrm{HO}$ of $16.7 \%$ with a $95 \%$ confidence interval of $4.6 \%$ to $28.9 \%{ }^{43}$

A potential benefit of the PEEK-on-ceramic materials used in the TDR evaluated in this study is the ability to perform MRI with minimal artifacts compared with that created by devices with metallic components. MRI is generally the imaging modality of choice to evaluate the cervical spine to assess the spinal canal, neuroforamina, intervertebral discs, and facet joints. In the current study, facet joints were assessed using a quantified scoring system, and no significant changes were found at the 24-month follow-up compared with the preoperative images. The lack of artifacts associated with the PEEK-onceramic device, which is nickel free, allowed MRI assessment of the spinal canal and exiting nerve roots with little or no distortion at the TDR level. As discussed by Sekhon et al, ${ }^{44}$ artifacts created by TDRs with metallic endplates, particularly with metals other than titanium, increase the need for computed tomography/myelography to evaluate the cervical spine. This introduces additional risks to the patient as well as costs. The results of this study found that the Simplify ${ }_{\circledast}$ Cervical Artificial Disc produced outcomes similar to or superior on some measures, including superiority in the composite success classification, compared with ACDF, for the treatment of single-level symptomatic cervical disc degeneration. The ROM at the treated level increased from the preoperative value and was maintained throughout follow-up. Safety of the PEEK-on-ceramic disc was established with no device failures in the series. These results support that the device is a viable alternative to ACDF.

\section{ACKNOWLEDGMENTS}

The authors would like to acknowledge the following principal investigators for their participation in this trial: Cameron Carmody, MD, and
Andrew Park, MD, Texas Spine Consultants, Addison, TX; Kris Radcliff, MD, Rothman Institute, Philadelphia, PA; William Taylor, MD, and Todd Allen, MD, University of California San Diego; Christopher Good, MD, Virginia Spine Institute, Reston, VA; Michael Janssen, DO, Spine Education and Research Foundation, Thornton, CO; Ashvin Patel, MD, Kennedy-White Orthopaedic Center, Sarasota, FL; Andrew Cappuccino, MD, Buffalo Spine Surgery, Lockport, NY; Jon I. White, MD, Orthopaedic Specialty Institute, Irvine, CA; Clint Hill, MD, and K. Brandon Strenge, MD, Orthopaedic Institute of Western Kentucky, and Andy Redmond, MD, Precision Spine Care, Tyler, TX.

\section{REFERENCES}

1. Zhai S, Li A, Li X, et al. Total disc replacement compared with fusion for cervical degenerative disc disease: a systematic review of overlapping meta-analyses. Medicine (Baltimore). 2020;99:e20143.

2. Wang QL, Tu ZM, Hu P, et al. Long-term results comparing cervical disc arthroplasty to anterior cervical discectomy and fusion: a systematic review and meta-analysis of randomized controlled trials. Orthop Surg. 2020;12:16-30.

3. Byvaltsev VA, Stepanov IA, Riew DK. Mid-term to longterm outcomes after total cervical disk arthroplasty compared with anterior diskectomy and fusion: a systematic review and meta-analysis of randomized controlled trials. Clin Spine Surg. 2020;33:192-200.

4. Kurtz SM, Devine JN. PEEK biomaterials in trauma, orthopedic, and spinal implants. Biomaterials. 2007;28:48454869.

5. Godlewski B, Dominiak M. Advantages and disadvantages of the use of various types of interbody implants in cervical spine surgery. Critical review of the literature. Ortop Traumatol Rehabil. 2020;22:213-220.

6. Brown T, Bao QB. The use of self-mating peek as an alternative bearing material for cervical disc arthroplasty: a comparison of different simulator inputs and tribological environments. Eur Spine J. 2012;21(suppl 5):S717-S726.

7. Song J, Xiang D, Wang S, et al. In vitro wear study of PEEK and CFRPEEK against UHMWPE for artificial cervical disc application. Tribology Int. 2018;122:218-227.

8. Siskey R, Ciccarelli L, Lui MK, et al. Are PEEK-onceramic bearings an option for total disc arthroplasty? An in vitro tribology study. Clin Orthop Relat Res. 2016;474:24282440 .

9. Xin H, Shepherd D, Dearn K. PEEK(polyether-etherketone) based cervical total disc arthroplasty: contact stress and lubrication analysis. Open Biomed Eng J. 2012;6:73-79.

10. Kraft M, Koch DK, Bushelow M. An investigation into PEEK-on-PEEK as a bearing surface candidate for cervical total disc replacement. Spine J. 2012;12:603-611.

11. Grupp TM, Meisel HJ, Cotton JA, et al. Alternative bearing materials for intervertebral disc arthroplasty. Biomaterials. 2010;31:523-531. 
12. Turner I, Choi D. Nunec ${ }^{\mathrm{TM}}$ cervical disc arthroplasty improves quality of life in cervical radiculopathy and myelopathy: a 2-yr follow-up. Neurosurgery. 2018;83:422-428.

13. Park PJ, Lehman RA. Optimizing the spinal interbody implant: current advances in material modification and surface treatment technologies. Curr Rev Musculoskelet Med. 2020;13:688-695.

14. Buck E, Li H, Cerruti M. Surface modification strategies to improve the osseointegration of poly(etheretherketone) and its composites. Macromol Biosci. 2020;20:e1900271.

15. Kurtz SM, Kocagöz S, Arnholt C, et al. Advances in zirconia toughened alumina biomaterials for total joint replacement. J Mech Behav Biomed Mater. 2014;31:107-116.

16. Coric D, Nunley PD, Guyer RD, et al. Prospective, randomized, multicenter study of cervical arthroplasty: 269 patients from the Kineflex $\mid \mathrm{C}$ artificial disc Investigational Device Exemption study with a minimum 2-year follow-up. $J$ Neurosurg Spine. 2011;15:348-358.

17. Silbergleit AK, Schultz L, Jacobson BH, et al. The Dysphagia Handicap Index: development and validation. Dysphagia. 2012;27:46-52.

18. McAfee PC, Cunningham BW, Devine J, et al. Classification of heterotopic ossification (HO) in artificial disk replacement. J Spinal Disord Tech. 2003;16:384-389.

19. Fujiwara A, Tamai K, Yamato M, et al. The relationship between facet joint osteoarthritis and disc degeneration of the lumbar spine: an MRI study. Eur Spine J. 1999;8:396-401.

20. Weishaupt D, Zanetti M, Boos N, et al. MR imaging and CT in osteoarthritis of the lumbar facet joints. Skeletal Radiol. 1999;28:215-219.

21. van Buuren S. Multiple imputation of discrete and continuous data by fully conditional specification. Stat Methods Med Res. 2007;16:219-242.

22. Rubin DB, Schenker N. Multiple imputation for interval estimation from simple random samples with ignorable nonresponse. J Am Stat Assoc. 1986;81:366-374.

23. Mummaneni PV, Burkus JK, Haid RW, et al. Clinical and radiographic analysis of cervical disc arthroplasty compared with allograft fusion: a randomized controlled clinical trial. J Neurosurg Spine. 2007;6:198-209.

24. Phillips FM, Lee JY, Geisler FH, et al. A prospective, randomized, controlled clinical investigation comparing $\mathrm{pcm}$ cervical disc arthroplasty with anterior cervical discectomy and fusion. 2-year results from the US FDA IDE clinical trial. Spine. 2013;38:E907-E918.

25. Vaccaro A, Beutler W, Peppelman W, et al. Clinical outcomes with selectively constrained secure-c cervical disc arthroplasty: two-year results from a prospective, randomized, controlled, multicenter Investigational Device Exemption study. Spine. 2013;38:2227-2239.

26. Hisey MS, Bae HW, Davis R, et al. Multi center, prospective, randomized, controlled investigational device exemption clinical trial comparing Mibi $\mathrm{C}^{\circledR}$ Cervical Artificial Disc to anterior discectomy and fusion in the treatment of symptomatic degenerative disc disease in the cervical spine. Int J Spine Surg. 2014;8. doi:10.14444/1007

27. Phillips FM, Coric D, Sasso R, et al. Prospective, multicenter clinical trial comparing M6-C compressible six degrees of freedom cervical disc with anterior cervical discectomy and fusion for the treatment of single-level degenerative cervical radiculopathy: 2-year results of an FDA
Investigational Device Exemption study. Spine J. 2021;21:239252.

28. Heller JG, Sasso RC, Papadopoulos SM, et al. Comparison of Bryan cervical disc arthroplasty with anterior cervical decompression and fusion: clinical and radiographic results of a randomized, controlled, clinical trial. Spine 2009;34:101-107.

29. Cai S, Tian Y, Zhang J, et al. Efficacy and safety of total disc replacement with anterior cervical discectomy and fusion in the treatment of cervical disease: a meta-analysis. Spine. 2020;45:1419-1425.

30. Synergy Disc Replacement Ltd. A multi-center, prospective, historically controlled pivotal trial comparing the safety and effectiveness of the Synergy disc to anterior cervical discectomy and fusion in patients with one-level symptomatic cervical degenerative disc disease (DDD). NCT 04469231. https://clinicaltrials.gov. Accessed June 10, 2021.

31. Womack W, Leahy PD, Patel VV, et al. Finite element modeling of kinematic and load transmission alterations due to cervical intervertebral disc replacement. Spine. 2011;36:E1126E1133.

32. Yuan $\mathrm{W}$, Zhang $\mathrm{H}$, Zhou X, et al. The influence of artificial cervical disc prosthesis height on the cervical biomechanics: a finite element study. World Neurosurg. 2018;113:e490-e498.

33. Kim KD, Karnati T, Permeswaran VN, et al. Changes in flexion/extension range of motion due to oversizing of cervical total disc arthroplasty. Spine J. 2019;19:S54.

34. Meng Y, Liu H, Wang XF, et al. Impact of artificial disc height on the morphology of cervical facet joint. Zhonghua $Y i$ Xue Za Zhi. 2019;99:3622-3626.

35. Liu J, Ebraheim NA, Haman SP, et al. How the increase of the cervical disc space height affects the facet joint: an anatomy study. Spine. 2006;31:E350-E354.

36. Wang X, Liu H, Meng Y, et al. Effect of disc height and degree of distraction on heterotopic ossification after cervical disc replacement. World Neurosurg. 2021;145: e100-e107.

37. Kim KS, Heo DH. Do postoperative biomechanical changes induce heterotopic ossification after cervical arthroplasty? A 5-year follow-up study. Clin Spine Surg. 2016;29:E309-E313.

38. Dong L, Tan MS, Yan QH, et al. Footprint mismatch of cervical disc prostheses with Chinese cervical anatomic dimensions. Chin Med J (Engl). 2015;128:197-202.

39. Spinal Kinetics.: M6-C Artificial Cervical Disc. Summary of Safety and Effectiveness Data (SSED); 2019. https://www. accessdata.fda.gov/cdrh_docs/pdf17/P170036B.pdf. Accessed April 1, 2021.

40. Globus Medical. Secure-C Cervical Artificial Disc. Summary of Safety and Effectiveness Data (SSED); 2012. https://www.accessdata.fda.gov/cdrh_docs/pdf10/P100003B. pdf. Accessed April 1, 2021.

41. LDR Spine. Mobi-C ${ }^{\circledR}$ Cervical Disc Prosthesis. Summary of Safety and Effectiveness Data (SSED); 2013. https://www. accessdata.fda.gov/cdrh_docs/pdf11/p110002b.pdf. Accessed April 1, 2021.

42. NuVasive. PCM Cervical Disc. Summary of Safety and Effectiveness Data (SSED); 2012. https://www.accessdata.fda gov/cdrh_docs/pdf10/P100012B.pdf. Accessed April 1, 2021.

43. Chen J, Wang X, Bai W, et al. Prevalence of heterotopic ossification after cervical total disc arthroplasty: a metaanalysis. Eur Spine J. 2012;21:674-680. 
44. Sekhon LH. Postoperative imaging of spinal disk arthroplasty devices. Semin Spine Surg. 2012;24:48-56.

Disclosures and COI: Guyer: Consulting: Simplify; Peloza: Speaking and/or Teaching Arrangements: Simplify Medical; Sasso: Research Support (paid directly to institution/employer) Simplify; Coric, Nunley, Musacchio, Bae, and Ohnmeiss: nothing to disclose.

Corresponding Author: Richard D. Guyer, MD, Center for Disc Replacement at Texas Back
Institute, 6020 West Parker Rd \#200, Plano, TX 75093. Phone: (972) 608-5000; Fax: (972) 608-5020; Email: rguyer@texasback.com.

Published 19 August 2021

This manuscript is generously published free of charge by ISASS, the International Society for the Advancement of Spine Surgery. Copyright (c) 2021 ISASS. To see more or order reprints or permissions, see http://ijssurgery.com. 